in animals have shown that it may occasionally attain the dimensions of subepithelial vesicles (1926).

Returning late one night from the laboratory suffering from an attack of photophthalmia contracted through carelessness some six hours previously from exposure to a mercury vapour lamp, my misery was to a considerable extent alleviated by observing a distinct halo round every street lamp. These halos were extremely beautiful, and were composed of inner rings of blue and violet and outer rings of yellow and red with a broad band of green in between. Subsequent examination showed that they were of the glaucomatous type, the angular diameter measured from the red ring was $12^{\circ}$, and they reacted to Druault's and Emsley and Fincham's tests. At the same time the tension of the eyes, as measured by Bailliart's scleral tonometer, was $18 \mathrm{~mm} . \mathrm{Hg}$, and finger pressure upon the eye had no effect upon the brightness or the size of the coloured rings. The distressing photophthalmic symptoms largely disappeared in eight hours, but the eyes remained congested for two days, and during these forty-eight hours the halos remained, gradually getting fainter and larger. This would appear to correspond with the disappearance of the droplets of oedema, since the optical conditions necessitate that the larger droplets cause small diffraction rings.

\title{
REFERENCES
}

Druault, A.-Arch. d'Ophtal., T. XL.. pp. 458, 536, 1923.

Duke-Elder, W. S.-Lancet, Vol. I, p. 1137, 1926.

Elliot, R. H. - A treatise on glaucoma. Oxford Med. Pubs., 2nd edition, p. 168, 1922 ; Amer. Jl. of Ophthal., Vol. VI, p. 1, 1923.

Emsley, H. H., and Fincham, E. F.-Amer. Jl. Physiol. Optics, Vol. IV, p. $247,1923$.

Koeppe, L.-Klin. Monatsbl. f. Augenheilk., Bd. LXV, S. 556, 1920.

Nordenson, W.-Sv. Läk. Handb., 1923.

Sheard, C.-Amer. Jl. of Ophthal., Vol. II, p. 185, 1919.

\section{DIRECT OPHTHALMOSCOPY IN HIGH MYOPIA}

\author{
BY \\ Alexander GarRow, M.D. \\ GLASGOW
}

THE examination of the fundus in myopia of high degree by direct ophthalmoscopy presents considerable difficulty and one has often to be satisfied with the indirect method. This has obvious drawbacks when one wishes to study minute details. Under such circumstances I have found that it is most helpful to make the direct examination with the patient wearing his glasses.

After I had made use of this method with increasing benefit for some time I looked through the chapters on ophthalmoscopy in a 
number of textbooks. In only one of these did I find a referenc. to the method. This is in the following sentences on page 384 of the eighth edition of Fuchs' textbook :

"A still better way of securing a clear image by the direct method particularly when either patient or observer is quite astigmatic or the patient has a high degree (12D. to 20D.) of myopia is for each to wear his correcting glasses, during the examination. Then the fundus is seen with great distinctness with the simple aperture or, if either patient or observer accommodates, with a weak concave lens."

My experience of the method convinces me that it is worthy of more extensive recommendation. The fundus of a high myope wearing the full correction and examined by direct ophthalmoscopy is as clearly seen as that of an emmetrope, and under a similar condition of magnification. Incidentally, too, one knows at once if the patient is wearing the full correction.

The details of the choroidal and other changes associated with high myopia can be accurately examined and the progress definitely appreciated from time to time, and pathological changes of the disc can be very clearly seen, as in a case of glaucomatous cupping with atrophy in a patient whom I see from time to time and who has over 20D. of myopia.

The method is even more useful in detecting lesser changes in the disc. In the ordinary direct ophthalmoscopic examination in the high degrees of myopia the whole field may be occupied by the disc and thus one does not get the same comprehensive view of it and the surrounding fundus as when the examination is made with the patient wearing his glasses. By the latter method, therefore, one gets the benefit of contrast between the disc and the surrounding fundus and it is thus more easy to appreciate departures from the normal colour of the disc.

There are certain difficulties in the method which have been minimized by practice. The greatest is the bright image of the light formed on the patient's glass. If this happens to be in the way, it can be got rid of by tilting his glass, and I find that a slight upward tilt is best. When an electric ophthalmoscope is being used this is easily done by holding the glass between the index finger and thumb of the unoccupied hand and slowly tilting the glass until the light image has been displaced from the pupillary area. When the peripheral portions of the field are being examined it is helpful to tilt the glass slightly towards the part examined.

When the ordinary ophthalmoscope is being used the method is more difficult and it is obviously necessary so to dispose the lamp and the hand which tilts the glass that there is no interference. with the light in its passage from its source to the mirror. 